\title{
Occupational Performance of Hearing-Impaired and Normal-Hearing Workers in Korea
}

\author{
Jinsook Kim ${ }^{1,2}$, Yerim Shin ${ }^{2}$, Seungwan Lee ${ }^{2}$, Eunsung Lee ${ }^{2}$, Woojae Han ${ }^{1,2}$, and Jihyeon Lee ${ }^{2}$ \\ ${ }^{1}$ Division of Speech Pathology and Audiology, College of Natural Sciences, Research Institute of Audiology and Speech Pathology, \\ Hallym University, Chuncheon, Korea \\ ${ }^{2}$ Department of Speech Pathology and Audiology, Graduate School, Hallym University, Chuncheon, Korea
}

Received March 16, 2021

Revised April 23, 2021

Accepted May 17, 2021
Background and Objectives: This study aimed to investigate the occupational performance of Korean workers with and without hearing loss and analyze the hearing-related difficulties in the working environment. Subjects and Methods: The Amsterdam checklist for hearing and work was used for the analyses and the occupational environments of the Korean workers were investigated. Out of 129 total participants, 86 workers experienced severe to profound hearing loss and 43 had the normal hearing ability. The hearing-impaired workers were recruited from two leading vocational centers and normal-hearing workers were their colleagues. Results: The hearing-impaired workers were found to take fewer sick leaves and exhibited higher rates of permanent job statuses compared to the normal-hearing workers. Workers with hearing loss rarely detected background sound; however, they could perceive reverberation more frequently. They felt more satisfied with their careers than the normal hearing workers as they received social support and needed to put their effort into hearing for most hearing activities. Furthermore, the effort in hearing increased with the increase in job demand, job control, social support, and career satisfaction. The working hours per week increased with the increase in age, education level, job demand, job control, and social support. Different trends were observed in 9 out of 12 variables while comparing the data from the present study with that obtained from the hearing-impaired workers of the Netherlands, indicating a large difference between countries. Conclusions: Although the hearing-impaired Korean workers operate diligently with good job positions, it is necessary to enhance their acoustic environment and provide them social support. Considering the cultural background of the hearing-impaired workers, the development of suitable vocational rehabilitation programs and specific questionnaires is strongly recommended worldwide.

J Audiol Otol 2021;25(4):189-198

Keywords: Occupational performance; Korean hearing-impaired workers; Amsterdam checklist for hearing and work; Acoustic environment; Vocational rehabilitation.

\section{Introduction}

Participation in the workforce is one of the significant events of life as defined by the International Classification of Functioning, Disability, and Health (ICF) of the World Health Organization [1]. Nevertheless, there are some difficulties that make impossible for people with "handicaps" to partici-

This is an Open Access article distributed under the terms of the Creative Commons Attribution Non-Commercial License (https://creativecommons.org/licenses/by-nc/4.0/) which permits unrestricted non-commercial use, distribution, and reproduction in any medium, provided the original work is properly cited. pate at work, which have been identified in the earlier version of the ICF. Although people with hearing impairment have recently gained several opportunities for employment with the improvement of welfare worldwide, hearing impairment seemed to influence their employment status [2]. For example, persons with communication disabilities experienced difficulties in coping at work for various reasons [3] and difficulties in maintaining a stable job [4]. In fact, the number of economically non-active individuals in the hearing and/or speech impaired population in Korea was 185,840 (65.0\%) out of 285,996, indicating a higher rate of nonparticipation than those ob- 
served among people with physical disability, mental retardation, and visual impairment in 2017 [5]. This high nonparticipation rate in comparison to other countries such as the United States and the United Kingdom might cause societal problems domestically $[6,7]$.

Although most functions other than communication skills are normal, it has been reported that workers with hearing impairment have difficulty maintaining a job for a long time $[8,9]$. The difficulties in communication and building personal relationships and differences in aptitude were reported to be the reasons [10]. The top 10 soft skills required at the workplace were integrity, communication, courtesy, responsibility, social skills, positive attitude, professionalism, flexibility, teamwork, and work ethic [11]. Among those, communication, social skills, teamwork, and flexibility were highly related to hearing sensitivity. Therefore, hearing ability was pointed to be essential in the modern workplace due to the greater demand for interpersonal qualities. Moreover, the hearing-impaired workers could be overlooked their work disparity because of the hidden nature of hearing loss [12].

Individuals with hearing impairment exhibited various differences in the working environment in comparison with normal-hearing workers, including work ability, style of job management, and mental stress management [13]. High stress at work was reported to originate from the imbalance between elevated job demands and low job control, which was common among 445 hearing-impaired workers in Sweden in one study [14]. Surprisingly, hearing-impaired workers were more sensitive to background noise than normal-hearing workers since their self-perceived rating for noise in the working environment appeared to be higher [15]. A noisy working environment could adversely influence listening ability in working conditions and induce more fatigue and stress, resulting in negative occupational performance [16]. Thus, workers with hearing loss might experience greater strain while participating in conversations and endure poor working environments.

Fortunately, the Amsterdam checklist for hearing and work was developed by researchers in the Netherlands to identify occupational difficulties in relation to hearing loss [10]. With this checklist, the researchers compared the occupational performance of employees with and without hearing loss to 150 hearing-impaired employees and 60 normal-hearing work colleagues. They found the workplace difficulties related to hearing impairments, including environmental noise level, reverberation, distinction of sounds, job demand, job control, and effort in hearing and discussed the importance of hearing functions and the implications for rehabilitation. Consequently, vocational enablement protocol, which was characterized as an integrated approach, was developed including hearing aid refit- ting, communication training, environmental modification including changes in furniture and lighting, allotment of separated work rooms, psychological counseling, the use of assistive listening devices, re-delegation of assignments, management of time schedules, and occupational retraining [17].

The Amsterdam checklist for hearing and work was used in two investigations on Icelandic and Norwegian workers. Böðvarsdóttir [18] assessed 46 workers with two questionnaires, the Amsterdam checklist for hearing and work and the Icelandic version of the General Nordic questionnaire for psychological and social factors at work, and found that both deaf individuals and those who were hard of hearing required social support. The researcher noted that the importance of developing a standardized assessment tool measuring psychological distress in workers with and without hearing difficulties. Investigating 3,330 Norwegian hearing-impaired workers using the Amsterdam checklist for hearing and work, hearing loss was found to impact work participation factors negatively. The authors concluded that greater attentiveness to hearingimpaired workers would reduce their experience of the disability [19].

However, no corresponding investigations have been conducted for hearing-impaired workers in Korea. Therefore, the Amsterdam checklist for hearing and work was translated into Korean with the consent of the authors through e-mail and verbal agreements and was applied for the assessment of Korean hearing-impaired workers (Supplementary Material in the online-only Data Supplement). The aim of this study was to compare the occupational performance of workers with hearing loss to that of their normal-hearing work colleagues. Also, comparing the difference hearing-related difficulties in the working environment experienced between the Netherlands and Korean hearing-impaired workers, the specific difficulties could be defined for the Korean workers. Identification of the specific difficulties at work and application of appropriate rehabilitation programs which has been shown to improve the welfare of hearing-impaired workers by making their working conditions more adaptive could be developed for Korean workers. The findings would increase the employment rate and the improvement of welfare of hearing-impaired workers would be possible in the future with suitable social support and effective communication for Korean hearing-impaired workers.

\section{Subjects and Methods}

\section{Subjects}

All participants were recruited from two institutes, "Vocational Training Center for the Hearing Impaired" of the Korean Employment Agency for the Disabled and "Chungeum Re- 
habilitation Center," which concentrated on employment of hearing-impaired individuals. Normal-hearing colleagues who performed essentially the same job at the same workplace as the hearing-impaired workers were invited to volunteer. They were all office worker and worked at the general environment of office. A total of 129 individuals ( 68 female, 61 male), including 86 hearing-impaired workers (38 female, 48 male) and 43 normal-hearing colleagues (30 female, 13 male), who were at the state of employment when they responded participated. The mean age of the study population was 34.04 years [17-58 years, standard deviation (SD): 11.04]; the mean age of the normal-hearing workers was 37.86 years $(23-63$ years, SD: 11.03), and the mean age of the hearing-impaired workers was 32.13 years (17-58 years, SD: 11.63). The current study applied the grading system of hearing disability in the Standards for Judgement of the Disability Grade (2018 year version). Among the hearing-impaired workers who participated in the current study, 78 were categorized as grade 2 that indicated pure tone average hearing thresholds above $90 \mathrm{~dB} \mathrm{HL}$ in both ears, 7 as grade 3 that indicated pure tone average hearing thresholds at $80-89 \mathrm{~dB} \mathrm{HL}$ in both ears, and 1 as grade 4 that indicated pure tone average hearing thresholds at 70-79 dB HL in both ears. When the educational levels (elementary, middle, high, undergraduate, and graduate school) were recorded on a scale of 1 to 5 , the average educational level was 3.62 (SD: 0.57) for the normal-hearing group and 3.22 (SD: 0.75) for the hearing-impaired group, indicating a lower educational level in the hearing-impaired group.

This study was approved by the Institutional Review Board of Hallym University (HIRB-2016-050).

\section{Instrument}

The survey instrument was the Amsterdam checklist for hearing and work that Kramer, et al. [10] developed. We adapted it via translation and back-translation from English to Korean with the authors' permission. It consisted of 28 items having three sections. Section 1 assesses the characteristics of the occupation and workplace; section 2 evaluates listening efforts in five hearing activities - detection of sounds, speech communication in quiet, speech communication in noise, distinguishing between sounds, and localization of sound; and section 3 assesses the general working conditions, including job demand, job control, career satisfaction, and social support. The participants are required to answer questions of the checklist themselves.

\section{Data analysis}

The generalized linear model multivariate analysis was applied to analyze the differences between the normal-hearing and hearing-impaired groups for multiple dependent variables. To analyze the relationship between the variables and hearing impairment, the analysis was done with four working conditions (job demand/job control/social support/career satisfaction); demographic information (age/sex/education level); type of contract (temporary status/permanent status); hearing impairment (yes/no) as independent variables. The Bonferroni approach was used to assess statistical significance by adjusting for multiple comparisons. All variables of the checklist were analyzed using Spearman rank correlation coefficients. Goodman and Kruskal's tau was selected to test the association between the hearing-impaired group and the variables of the questions required yes and no answer choosing one out of two item variables such as "sick-leave," "reason for sick-leave," and "type of contract." Statistical analyses were performed using SPSS version 23.0 (IBM Corp., Armonk, NY, USA) with a significance level of 0.05 .

\section{Results}

\section{Daily activities at workplace and educational levels}

When counted the daily activities at the workplace for both groups, "administrative" activity was the most frequent activity for both groups, showing a lower rate for the hearing-impaired workers. Moreover, "telephone conversation" for the normal-hearing group and "teaching" for the hearing-impaired group were other frequent daily activities. The hearing-impaired and normal-hearing groups respectively included 2.3\% and $0 \%$ elementary school graduates, $9.3 \%$ and $2.3 \%$ middle school graduates, $55.8 \%$ and $34.9 \%$ high school graduates, $39.1 \%$ and $60.6 \%$ university undergraduates, and $3.5 \%$ and $2.3 \%$ university postgraduates. The university undergraduate and high school graduate levels demonstrated the largest number of participants in the normal-hearing and hearing-impaired groups respectively.

\section{Differences between normal-hearing and hearing- impaired workers in the Amsterdam checklist for hearing and work}

The overall multivariate analysis of variance revealed a significant group effect $[\mathrm{F}(124,1)=4.536, p<0.05]$, indicating that hearing-impaired workers responded differently from their normal-hearing colleagues in several aspects. The means, SD, and levels of significance of the variables were outlined in Table 1 . When the type of contract was compared with respect to temporary and permanent statuses, 35\% (15 out of 43 ) of those with normal hearing and $47 \%$ (41 out of 86 ) of those with hearing impairments reported that they had permanent job statuses $[\mathrm{F}(124,1)=4.231, p<0.05]$. However, when the 
Table 1. Comparison of the results between normal-hearing and hearing-impaired workers using the translated Amsterdam checklist for hearing and work into Korean

\begin{tabular}{|c|c|c|c|}
\hline Variables & Normal-hearing & Hearing-impaired & p-value \\
\hline Hours of work per week & $42.06(13.6)$ & $31.25(16.2)$ & n.s. \\
\hline Workdays per week & $5.0(0)$ & $5.0(0)$ & n.s. \\
\hline Number of sick-leave days in the past 12 months & $1.05(1.92)$ & $0.51(0.99)$ & $p<0.05$ \\
\hline \multicolumn{4}{|l|}{ Frequency of hearing activities* ${ }^{\dagger}$} \\
\hline Detection of sounds & $1.8(1.0) / 1.8(1.1)$ & $1.3(0.9) / 1.8(1.1)$ & $p<0.05$ \\
\hline Speech communication in noise & $1.7(1.1) / 1.9(1.1)$ & $1.5(1.1) / 1.7(1.1)$ & n.s. \\
\hline Speech communication in quiet & $2.0(1.0) / 1.7(0.9)$ & $1.7(1.1) / 1.8(1.2)$ & n.s. \\
\hline Distinguishing sounds & $1.7(0.9) / 1.8(1.0)$ & $1.6(1.1) / 1.8(1.2)$ & n.s. \\
\hline Localization of sounds & $1.4(0.8) / 1.7(1.0)$ & $1.7(1.2) / 1.9(1.3)$ & n.s. \\
\hline \multicolumn{4}{|l|}{ Working environment* } \\
\hline Self-perceived environmental noise & $1.7(1.1)$ & $1.7(0.8)$ & n.s. \\
\hline Self-perceived reverberation & $1.4(1.0)$ & $1.7(0.7)$ & $p<0.05$ \\
\hline \multicolumn{4}{|l|}{ Effort and concentration* } \\
\hline Effort in hearing & $1.7(0.7)$ & $1.6(0.9)$ & n.s. \\
\hline \multicolumn{4}{|l|}{ General working conditions* } \\
\hline Job demand & $1.9(0.7)$ & $1.7(0.7)$ & n.s. \\
\hline Job control & $1.7(0.7)$ & $1.7(0.8)$ & n.s. \\
\hline Social support & $2.1(0.8)$ & $2.1(0.9)$ & n.s. \\
\hline Career satisfaction & $1.8(0.6)$ & $2.0(0.7)$ & n.s. \\
\hline Type of contract (temporary/permanent) & $28 / 15$ & $45 / 41$ & $p<0.05$ \\
\hline Type of contract (full-time/part-time) & $43 / 0$ & $86 / 0$ & n.s. \\
\hline Sick-leave in the past 12 months (no/yes) & $25 / 18$ & $58 / 28$ & $p<0.05$ \\
\hline Reason for sick-leave (other/mental distress) & $18 / 0$ & $28 / 0$ & n.s. \\
\hline
\end{tabular}

Values are presented as mean (standard deviation) or number only. *The scores for each question are $1-4$ scales, ${ }^{\dagger}$ The results of frequency of hearing activities are indicated as the score of question 'a' regarding frequency and 'b' regarding effort in hearing. n.s.: non-significant

type of contract was compared between full- and part-time positions, $100 \%$ of the participants in both groups reported having full-time jobs. Absences for sickness appeared to be a slightly higher in the normal-hearing group, $42 \%$ (18 out of 43), than in the hearing-impaired group, 33\% (28 out of 86 ) [F(124, $1)=4.752, p<0.05]$. The reasons for sick-leaves included all reasons other than mental distress in both groups. The mean number of sick-leave days in the past 12 months was greater than one (1.05) in the normal-hearing workers and less than one $(0.51)$ in the hearing-impaired workers, with the difference showing a statistical significance. In the classification of the frequency of hearing activities, "detection of sounds" was the only variable that showed a difference between the groups, with the normal-hearing group reporting more instances of detection of background sounds $[\mathrm{F}(124,1)=4.939, p<0.05]$. Out of the two questions for the classification of the working environment, only "self-perceived reverberation" showed a statistical significance, with higher scores in the hearing-impaired workers $[\mathrm{F}(124,1)=4.018, p<0.05]$.

None of the variables in the categories of "effort and concentration" and "general working conditions" demonstrated a statistical significance. Although "hours of work per week" also did not show statistically significance, normal-hearing workers reported that they worked 10.81 hours more than hearing-impaired workers weekly. Notably, the scores for "workdays per week" (5 days in both groups), "self-perceived environmental noise," "job control," and "social support" were identical scores in the two groups.

The Spearman rank correlation coefficients of all variables involved in this study are outlined in Table 2 . The three highest positive correlations were observed between "social support" and "career satisfaction" $(\mathrm{r}=0.766)$, "distinguishing sounds" and "effort in hearing" ( $\mathrm{r}=0.712)$, and the "localization of sounds" and "effort in hearing" $(r=0.695)$. The three highest negative correlations were found between "grade of HD" and "hours per week" (r=-0.313), "grade of HD" and "education" ( $\mathrm{r}=-0.288)$, and "grade of HD" and "age" ( $\mathrm{r}=-0.247)$. The "sex" ( $r=0.237)$, "age" $(r=0.456)$, and "education" $(r=$ 0.192 ) showed significant correlations with "hours per week". The "hours per week" showed a positive correlation with the general working conditions including "job demand" $(r=$ 0.369), "job control" ( $\mathrm{r}=0.216)$, "social support" $(\mathrm{r}=0.184)$, 
Kim J, et al.

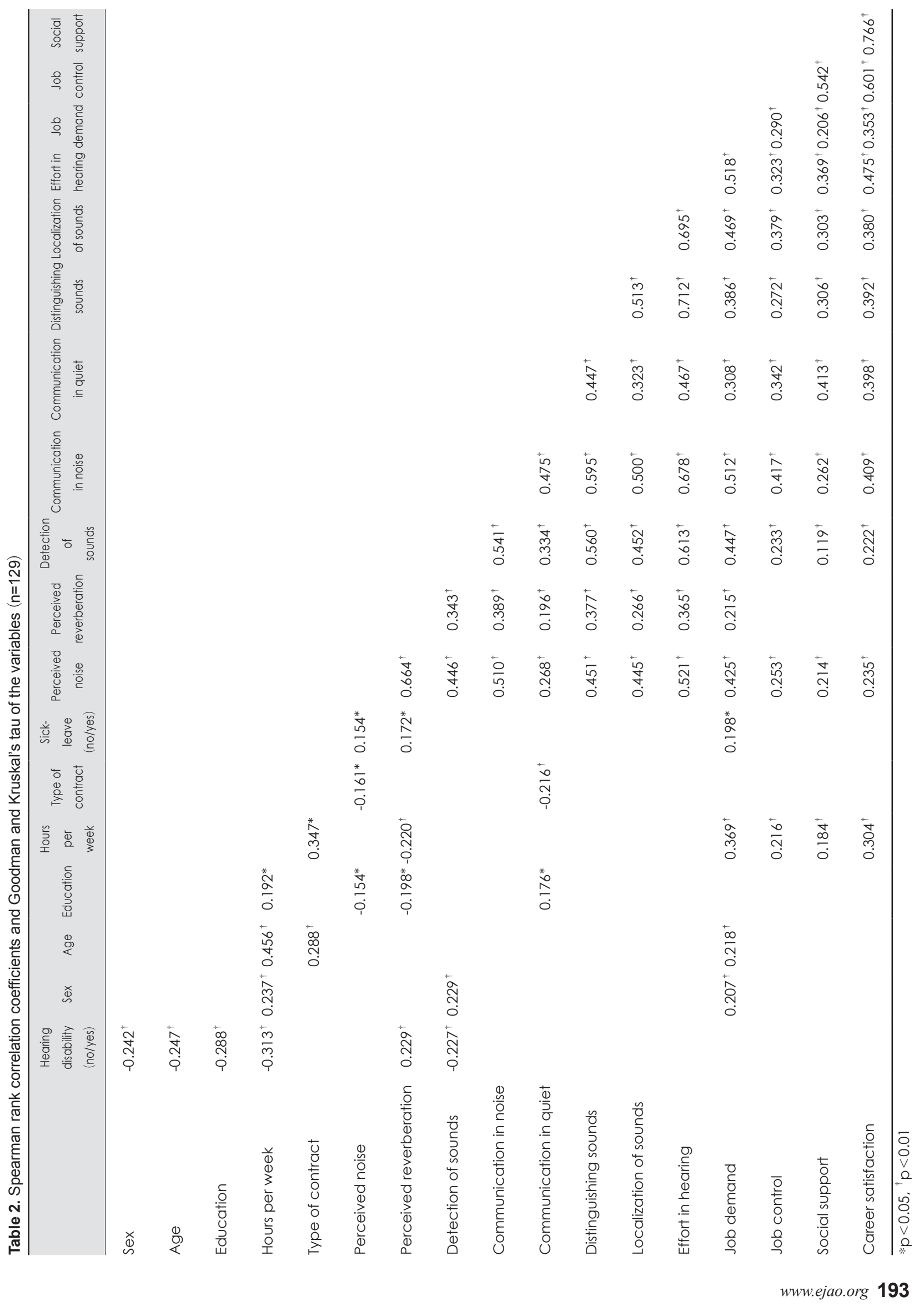


and "career satisfaction" ( $\mathrm{r}=0.304)$. The variable "effort in hearing" was significantly correlated with all the variables in the classification of hearing activity. Two variables from the classification of the working environment, "perceived noise" and "perceived reverberation," were significantly correlated with all the variables in the classifications of hearing activity and effort in hearing. All variables of the classification of hearing activity were significantly correlated with variables in the classification of general working conditions. "Effort in hearing" was significantly correlated with all the variables in the classification of general working conditions.

\section{Comparison of working environment and difficulties between Korean and Dutch hearing-impaired workers}

Since this study was conducted using almost the same methods as the earlier study of the Amsterdam checklist for hearing and work [10], it was possible to compare the working environment and difficulties of hearing-impaired workers from Korea and the Netherlands. Surprisingly, the results of the two studies were quite different (Fig. 1). For workers from both countries, the question "speech communication in quiet" showed lower scores and the questions "localization of sounds" and "self-perceived reverberation" revealed higher scores in the hearing-impaired group. Six variables, "detection of sounds," "speech communication in noise," "distinguishing sounds," "effort in hearing," "job demand," and "career satisfaction" demonstrated dissimilar patterns between the two countries. While "self-perceived environmental noise" and "job control" showed identical scores between the normal-hearing and hear- ing-impaired groups in Korean study, higher scores in the hearing-impaired group was identified in Dutch study. Also, while the scores for "social support" were the same for both normalhearing and hearing-impaired workers in Korean study, the scores were much lower for hearing-impaired workers in Dutch study. When the variables assessed using 5-point scales in questionnaires were compared between the normal-hearing and hearing-impaired groups, only two variables, "detection of sounds" and "self-perceived reverberation" showed statistical significance in Korean study, whereas six variables, "speech communication in noise," "distinguishing sounds," "localization of sounds," "self-perceived environmental noise," "effort in hearing," and "job control" were significantly different in Dutch study. For "type of contract," "sick-leave in the past 12 months," and "reason for sick-leave," in which participants needed to choose one out of two items, the results were significantly different for two countries. The higher ratios of permanent job contraction and the full-time job for Korean hearing-impaired workers were revealed. Moreover, unlike the findings in the Dutch study, the Korean normal-hearing group did not show a higher rate of sick-leaves in the past 12 months, nor did the Korean hearing-impaired group report a higher proportion of sick-leaves with mental distress as the reason (Fig. 2).

\section{Discussion}

When compared with the normal-hearing workers, hearing-impaired workers had $12 \%$ more permanent job statuses

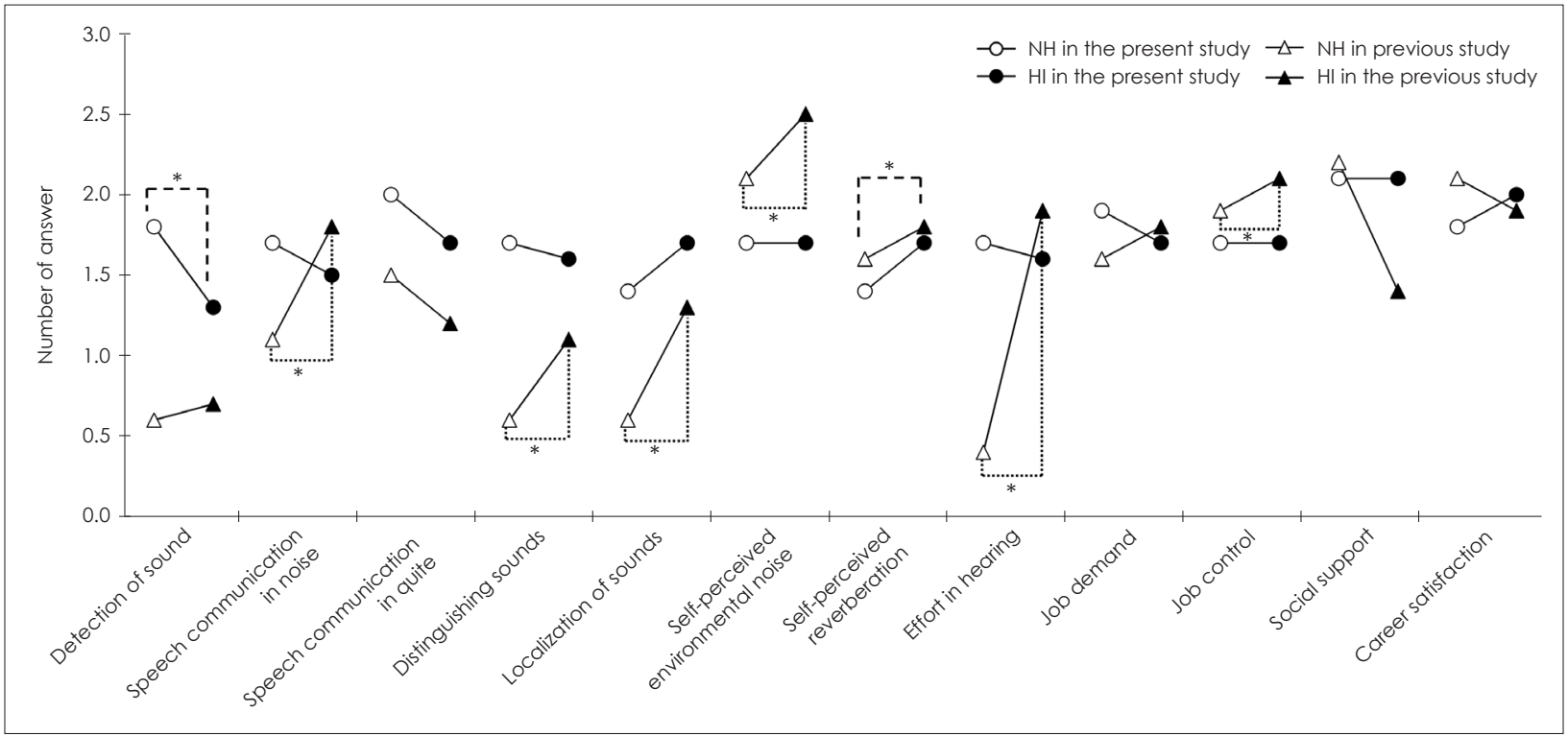

Fig. 1. Mean scores of the variables assessed in a general linear mode with the levels of significance from Korean and Netherlands workers. Dashed and dotted lines depict the statistical findings from Korea and Netherlands, respectively. ${ }^{*} p<0.05$. $\mathrm{NH}$ : normal-hearing, $\mathrm{HI}$ : hearing-impaired. 
Fig. 2. The ratios of contract type and sick-leave in the past 12 months among $\mathrm{NH}$ and $\mathrm{HI}$ groups in the current and earlier studies. ${ }^{*} p<0.05 . \mathrm{KW}$ : Korean workers, NW: the Netherlands workers, $\mathrm{NH}$ : normal-hearing, $\mathrm{HI}$ : hearing-impaired.

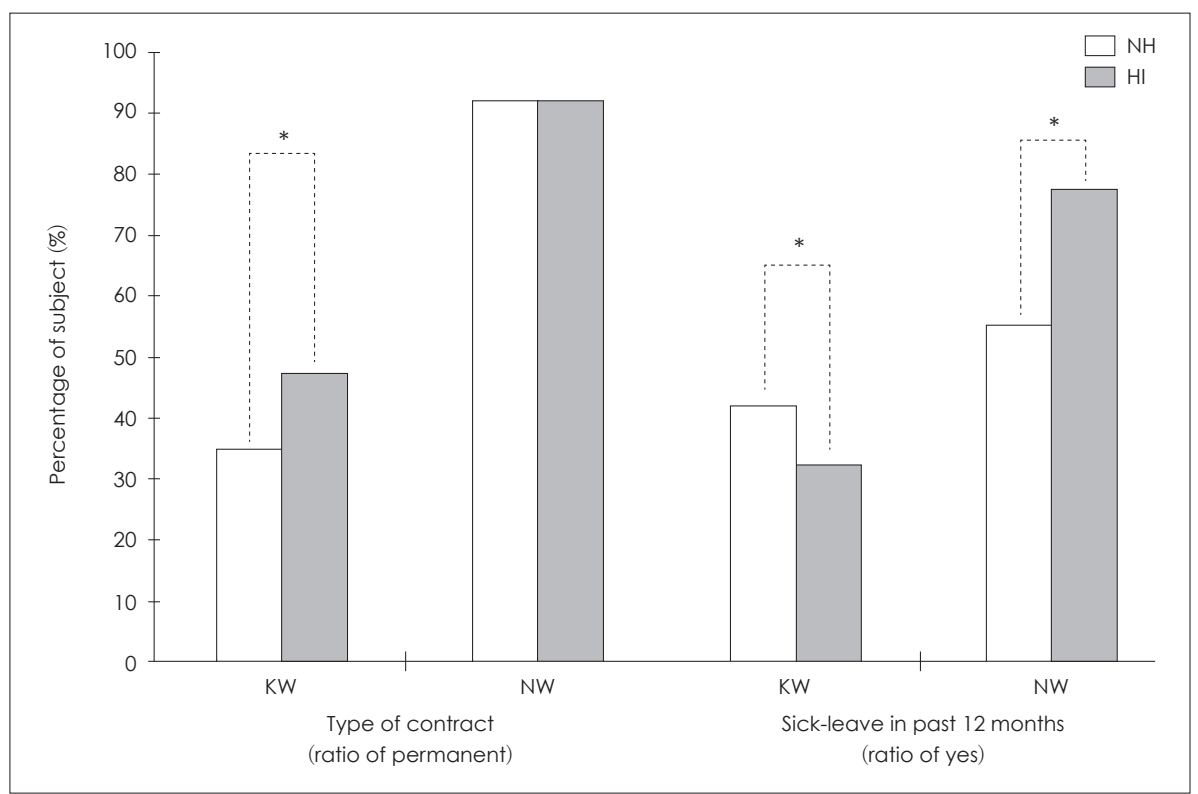

and 100\% full-time jobs and showed 9\% lower rates of sickleaves in Korea. They detected sounds less frequently and perceived reverberation more frequently at the workplace. They felt more satisfied with their career as they got more social support. "Effort in hearing" was necessary for better performance in most hearing activities such as detection of sounds, communication in noise, and distinguishing and localizing sounds. The number of hours worked per week increased as age, perceived reverberation, job demand, and job career satisfaction increased. When compared the results of the normal-hearing and hearing-impaired workers between Korea and the Netherlands, the same trends were observed in three variables. The trends of speech communication in quiet showed lower scores but self-perceived reverberation and localizing sounds showed higher scores in the hearing-impaired workers for both countries. Especially, the hearing-impaired workers from both countries reported localization of sounds more frequently than the normal-hearing workers. It was thought that the hearing-impaired workers might have felt more necessarily for localizing sounds due to the hearing loss. However, speech in noise, detecting and distinguishing sounds, perceiving environmental noise, effort in hearing, job demand, job control, social support, and carrier satisfaction variables showed different trends. Out of those variables, effort in hearing and job demand were reported to be slightly higher in Korean normal-hearing workers even though its difference was not significant. This small difference happened possibly due to more workload built to the normal-hearing workers, causing more effort in hearing and job demand appear.

The correlation coefficient results in this study revealed the consistency between variables. A high correlation between "social support" and "career satisfaction" implied that workers who received adequate social support from colleagues would achieve career satisfaction. Nevertheless, this form of social support seemed to be more common at higher severities of hearing loss, since a previous study reported that the deaf group received better social support than the hard of hearing group [18]. It is possible that social support was adequately given to people with remarkable impairment, including severe to profound hearing loss. Moreover, the likelihood of workplace accommodation increased with an increasing degree of hearing loss [19]. However, in the present study, $90.6 \%$ of hearing-impaired participants were categorized into profound hearing loss, and the hearing-impaired workers received the same level of social support as normal-hearing workers. A good conceptual overview of social support was described in the literature identifying four attributes such as emotional support, instrumental support, informational support, and appraisal [20]. Simply, social support at the workplace could be provided when supervisors could be helpful and colleagues would be friendly. Specifically, a helpful supervisor was described with the characteristics "being concerned," "good organizing," and "paying attention." The primary characteristics of a friendly colleague were "helpful," "interested," and "competent" [21]. Males, older participants, those with higher education levels, and those with better hearing ability were more likely to work longer. This trend was observed as a similar phenomenon for typical Korean workers [22].

"Effort in hearing" was correlated with differentiation and localization of the sounds at the workplace. It appeared to be remarkably associated with all variables in the classification of hearing activity such as detection of sounds, speech com- 
munication in quiet, speech communication in noise, and distinguishing and localizing sounds proving that hearing-impaired workers needed to put their effort in hearing almost always. Furthermore, the inability to hear non-verbal contextual sounds would generate psychological distress and loss of control of the situation [23] increasing the degree of effort for hearing at the workplace. This kind of worker's effort in hearing was known to be the cause of a highly stressful life, including stress and fatigue, when it was related to job demand, job control, and occupational risks [14]. Two variables from the categories of working environment, perceived noise and reverberation, were also remarkably associated with "effort in hearing." In this poor working environment, workers were required to put more "effort in hearing" and consequently get more fatigued and mentally distressed, and the findings agreed with the argument that the aspect of effort in hearing deserved more attention [10].

The "perceived level of noise" $(\mathrm{r}=0.510)$ and "perceived reverberation" ( $r=0.389)$ showed notable associations with the frequency of experiencing "communication in noise" at work, showing that workers who communicated frequently in noisy backgrounds perceived more environmental noise and reverberation in their work life. The negatively correlated variables were "type of contract" and "communication in quiet" ( $r=-0.216)$ and "hours per week" and "perceived reverberation" ( $r=-0.220)$. Thus, permanent employees communicated less frequently in quiet environments, and the workers who worked more hours perceived less reverberation. Again, in poor working environments, stronger "effort in hearing" was essential, which prompted mental and physical exhaustion among the hearing-impaired workers. As all participants worked in comparable environments, the background noise level and perceived reverberation were expected to be the same for both the normal-hearing and the hearing-impaired workers. However, the hearing-impaired workers perceived more "self-perceived reverberation" in this study. The previous studies explained that hearing-impaired workers were more sensitive to the background noise than normal-hearing workers [16] and speech recognition scores of hearing-impaired workers quickly decreased with increasing reverberation [24]. Considering the general agreement among investigators for this factor, many studies attempted to resolve the problems encountered at the workplace for the hearing-impaired by using a rehabilitative process $[1,25,26]$. Many contents were presented as the results of the studies. For example, environmental modifications for improving acoustical environments including the optimal arrangement of the furniture at the workplace, improvement of room acoustics using carpets and curtains, and the provision of light were suggested.
Most hearing-impaired participants in this study had severe or profound hearing loss for a long duration. Most participants were graduates of high schools with an average age of 32.13 years. The educational level among the hearing-impaired participants was consistent with that in the Netherlands [10]. Hearing impairment with lower education affected both education and employment status [2]. However, in comparison with Norwegian and Icelandic studies, which reported that most hearing-impaired participants were college graduates [18, 19], the educational level was lower in the participants of this study. In fact, most participants in the hearing-impaired and normal-hearing groups were at the high school graduate and university graduate levels, respectively. Moreover, lower education levels were correlated with noisy working environments $(\mathrm{r}=-0.154)$, implying that the working environments of employees with lower education levels was noisier. The job quality in such noisier working environments could also be expected to be low. While "job control" and "social support" scored the same in hearing-impaired and normal-hearing workers, the results for the hearing-impaired workers indicated less "job demand," less "effort in hearing," and more "career satisfaction" in this study.

Korean workers worked more hours and took fewer sickleave days than those in the Netherlands. When the normalhearing and hearing-impaired groups were compared, "hours of work per week" were 31.4 and 31.7 for the Netherlands workers without and with hearing loss, respectively, and 42.06 and 31.3 for Korean workers. Similarly, the "number of sickleave days in the past 12 months" were 6.01 and 26.31 for the Netherlands workers and 1.05 and 0.51 for Korean workers. This trend was well demonstrated by the high Korean national rates of no sick-leave days, about $87 \%$ and $97 \%$, for both normal-hearing and hearing-impaired groups. Also, similar to the result of the present investigation, the average "hours of work per week" was found to be over 40 hours, as the working hours were identified to be less than 40 hours per week for $52 \%, 41-52$ hours per week for $27 \%$, and more than 53 hours per week for $21 \%$ of all Korean workers. This phenomenon could be related to the general work attitude and unique cultural values of Korean workers. Korean workers are known to be diligent, loyal, and committed to their employers, and their high performance has been identified as a reason for Korea's rapid industrialization in cross-cultural studies [27,28]. Thus, Korean workers appeared to exert themselves as much as possible to accept any kind of hearing activity. This might have caused more physical and mental fatigue among the hearing-impaired workers, even though they did not complain about it. Moreover, Korean hearing-impaired workers took significantly fewer sick-leave days for both the normal-hear- 
ing and hearing-impaired workers than other countries [10,29]. A deep-rooted philosophy in Korean society, Confucianism, possibly played a role for placing high value on hard work, loyalty, responsibility, dedication to duty, and achievement-oriented education for most workers [27]. Therefore, the working hours should be controlled adequately so that the workers can work more effieciently and prevent stress from working environment. Also, more number of sick-leave days should be provided to the employees and more supportive atmosphere for taking sick-leave should be provided for the hearing-impaired workers.

The present study noted that hearing-impaired workers perceived reverberation more frequently and background noise less frequently. Consequently, "effort in hearing" was necessary for most hearing activities for better performance at work. Based on these findings, we can conclude that there is a need for increased awareness of working environment such as reverberation. In terms of noise and reverberation, proper modifications for the working environment like carpets, curtains, copiers, and printers are strongly recommended at the workplace. Social support seems to be an important factor in increasing career satisfaction and the employment rate for hearing-impaired workers. Considering cultural differences, specific questionnaires should be developed for each country. Even though this study investigated the occupational performance of Korean workers with and without hearing loss, the limitation of recruiting participants was existed.

\section{Supplementary Materials}

The online-only Data Supplement is available with this article at https://doi.org/10.7874/jao.2021.00185.

\section{Acknowledgments}

The authors thank to Joong-O Yoon and Gaewon Shim for recruiting all the participants from two institutes, "Vocational Training Center for the Hearing Impaired" of the Korean Employment Agency for the Disabled and "Chungeum Rehabilitation Center," which concentrated on employment of hearing-impaired individuals.

This work was supported by Hallym University Research Fund (HRF-201808-008).

\section{Conflicts of interest}

The authors have no financial conflicts of interest.

\section{Author Contributions}

Conceptualization: Jinsook Kim and Woojae Han. Data curation: Seungwan Lee, Eunsung Lee, Woojae Han, and Jihyeon Lee. Formal analysis: Seungwan Lee and Eunsung Lee. Funding acquisition: Jinsook Kim. Investigation: Jinsook Kim, Yerim Shin, Woojae Han, and Jihyeon Lee. Methodology: Jinsook Kim, Eunsung Lee, Woojae Han, and Jihyeon Lee. Project administration: Jinsook Kim and Yerim Shin. Supervision: Jinsook Kim. Writing — original draft: Jinsook Kim, Seungwan Lee, and Eunsung Lee. Writing — review \& editing: Yerim Shin and Woojae Han. Approval of final manuscript: all authors.

\section{ORCID iDs}

Jinsook Kim

Yerim Shin

Seungwan Lee

Eunsung Lee

Woojae Han

Jihyeon Lee

https://orcid.org/0000-0003-3440-2393

https://orcid.org/0000-0002-2914-6711

https://orcid.org/0000-0002-5875-9971

https://orcid.org/0000-0001-6525-3533

https://orcid.org/0000-0003-1623-9676

https://orcid.org/0000-0003-0896-9062

\section{REFERENCES}

1) World Health Organization. International classification of functioning, disability and health: children and youth version: ICF-CY. Geneva: World Health Organization;2007.

2) Järvelin MR, Mäki-Torkko E, Sorri MJ, Rantakallio PT. Effect of hearing impairment on educational outcomes and employment up to the age of 25 years in northern Finland. Br J Audiol 1997;31:165-75.

3) Thomas A, Lamont M, Harris M. Problems encountered at work by people with severe acquired hearing loss. Br J Audiol 1982;16:39-43.

4) Meulenbroek P, Turkstra LS. Job stability in skilled work and communication ability after moderate-severe traumatic brain injury. Disabil Rehabil 2016;38:452-61.

5) Park HW, Kim HJ, Bahng JK, Lim YJ, Yoo WS, Kim UA, et al. Survey on the economic activities of disabled persons, 2017. Seongnam: Korea Employment Agency for the Disabled;2017.

6) Kraus L, Lauer E, Coleman R, Houtenville A. 2017 disability statistics annual report. Durham: University of New Hampshire;2018.

7) Powell A. Disabled people in employment [Internet]. House of Commons Library; 2021 [cited 2021 Jan 11]. Available from: URL: https://commonslibrary.parliament.uk/research-briefings/cbp-7540/ \#fullreport.

8) Jang CY, Lee DY, Kim HY, Ahn TH, Choi J. Vocational rehabilitation and employment promotion plan for the hearing impaired. Seongnam: Korea Employment Agency for the Disabled;2004.

9) Nam YH, Jang EH. A study on the phenomenological of the deaf to experience and job maintaining. Disability \& Employment 2009;19: 55-78.

10) Kramer SE, Kapteyn TS, Houtgast T. Occupational performance: comparing normally-hearing and hearing-impaired employees using the Amsterdam Checklist for Hearing and Work. Int J Audiol 2006; 45:503-12.

11) Robles MM. Executive perceptions of the top 10 soft skills needed in today's workplace. Bus Commun Q 2012;75:453-65.

12) Shaw L, Jennings MB, Kramer SE. Work transition tips: inclusion for workers with hearing loss: actions for work practice professionals. Work 2013;46:205-6.

13) Punch R. Employment and adults who are deaf or hard of hearing: current status and experiences of barriers, accommodations, and stress in the workplace. Am Ann Deaf 2016;161:384-97.

14) Danermark B, Gellerstedt LC. Psychosocial work environment, hearing impairment and health. Int J Audiol 2004;43:383-9.

15) McGarrigle R, Munro KJ, Dawes P, Stewart AJ, Moore DR, Barry JG, et al. Listening effort and fatigue: what exactly are we measuring? A British Society of Audiology Cognition in Hearing Special Interest Group 'white paper.' Int J Audiol 2014;53:433-40.

16) Jahncke H, Halin N. Performance, fatigue and stress in open-plan offices: the effects of noise and restoration on hearing impaired and normal hearing individuals. Noise Health 2012;14:260-72.

17) Kramer SE. Hearing impairment, work, and vocational enablement. Int J Audiol 2008;47 Suppl 2:S124-30.

18) Böðvarsdóttir bÓ. Job satisfaction and well-being among deaf and hard of hearing employees in Iceland [dissertation]. Reykjavík: Reykjavik University;2017.

19) Svinndal EV, Solheim J, Rise MB, Jensen C. Hearing loss and work participation: a cross-sectional study in Norway. Int J Audiol 2018; 
57:646-56.

20) Langford CP, Bowsher J, Maloney JP, Lillis PP. Social support: a conceptual analysis. J Adv Nurs 1997;25:95-100.

21) Eum KD, Li J, Jhun HJ, Park JT, Tak SW, Karasek R, et al. Psychometric properties of the Korean version of the job content questionnaire: data from health care workers. Int Arch Occup Environ Health 2007;80:497-504.

22) Statistics Korea. Economically active population survey in July 2017 [Internet]. Statistics Korea; 2017 [cited 2020 Dec 19]. Available from: URL: http://kostat.go.kr/portal/eng/pressReleases/5/2/index.board?b mode $=$ read $\& b S e q=\& a S e q=362132 \&$ page $N o=4 \&$ rowNum $=10 \&$ nav Count $=10 \&$ currPg $=\&$ searchInfo $=\&$ sTarget $=$ title \&sTxt $=$.

23) Eriksson-Mangold MM, Erlandsson SI. The psychological importance of nonverbal sounds. An experiment with induced hearing deficiency. Scand Audiol 1984;13:243-9.

24) Crandell CC, Smaldino JJ. Classroom acoustics for children with normal hearing and with hearing impairment. Lang Speech Hear Serv Sch 2000;31:362-70
25) Gussenhoven AHM, Anema JR, Witte BI, Goverts ST, Kramer SE. The effectiveness of a vocational enablement protocol for employees with hearing difficulties: results of a randomized controlled trial. Trends Hear 2017;21:2331216517692304.

26) Jennings MB, Shaw L, Hodgins H, Kuchar DA, Bataghva LP. Evaluating auditory perception and communication demands required to carry out work tasks and complimentary hearing resources and skills for older workers with hearing loss. Work 2010;35:101-13.

27) Bae K, Chung C. Cultural values and work attitudes of Korean industrial workers in comparison with those of the United States and Japan. Work Occup 1997;24:80-96.

28) Lincoln JR, Kalleberg AC. Culture, control and commitment: a study of work organization and work attitudes in the United States and Japan. New York: Cambridge University Press; 1992.

29) Nachtegaal J, Festen JM, Kramer SE. Hearing ability in working life and its relationship with sick leave and self-reported work productivity. Ear Hear 2012;33:94-103. 


\section{Supplementary Material}

\section{The Translated Amsterdam Checklist for Hearing and Work into Korean \\ Among the Questions, Number 13 is Only Included for the Hearing-Impaired}

1. 당신의 직업은 무엇입니까?

2. 당신은 일주일에 몇 시간 정도 직장에서 근무하십 니까?

3. 계약직입니까? 정규직입니까?

4. 지난12개월 동안, 아파서 결근하거나 조퇴한 경우 가 며칠입니까?

5. 다음 중 직장에서 당신의 주요 업무는 무엇입니까?

6a. 근무지에서 환경 소음을 인지하십니까?

6b. 근무지에서 반향(소리가 울려서 퍼지게 들림)이 느 껴지십니까?

7a. 직장에서 얼마나 자주 소리(경고음)들을 감지해야 할 필요가 있습니까?

7b. 그 소리를 감지하기 위해 얼마만큼의 노력과 집중 이 필요합니까?

8a. 직장에서 얼마나 자주 소음 속에서 대화를 해야 합 니까?

$8 b$. 소음 속에서 대화를 하기 위해 얼마만큼의 노력과 집중이 필요합니까?

9a. 직장에서 얼마나 자주 조용한 상황에서 대화를 합 니까?

9b. 조용한 상황에서 대화를 하기 위해 얼마만큼의 노 력과 집중이 필요합니까?

10a. 직장에서 얼마나 자주 여러 소리(목소리와 신호음 등)를 구별해야 합니까?

10b. 여러 소리를 구별하기 위해 얼마만큼의 노력과 집 중이 필요합니까?

11 a. 직장에서 얼마나 자주 소리가 나는 곳을 파악해야 할 필요가 있습니까?

$11 \mathrm{~b}$. 소리의 위치를 파악하기 위해 얼마만큼의 노력과 집중이 필요합니까?
12. 당신의 직업은 정신적으로 스트레스를 줍니까?

13. 당신의 직업은 정상 청력의 동료보다 당신에게 더 많이 스트레스를 줍니까?

14. 작업을 끝내기 위해 시간이 부족했던 적이 가끔 있 습니까?

15. 하루의 작업을 마치고 매우 지친다고 느낍니까?

16. 원할 때마다 당신은 작업을 잠시 중단할 수 있습니까?

17. 직장에서 업무 내용을 스스로 결정할 수 있습니까?

18. 직장에서 자신의 업무 내용을 스스로 선택하고 구성 할 수 있습니까?

19. 스스로 업무 시작 시간, 종료 시간, 휴식 시간들을 결정할 수 있습니까?

20. 당신의 일을 즐기고 있습니까?

21. 전반적으로 직장 분위기가 좋다고 생각합니까?

22. 당신의 업무에 대해 직속 상관으로부터 충분한 지원 을 받고 있습니까?

23. 현재의 직업에 만족합니까?

24. 직장에서 당신의 능력을 개발할 수 있습니까?

25. 당신은 주로 단조로운 업무를 많이 합니까?

26. 본인의 업무에 관하여 결정할 수 있는 권한이 있습 니까?

27. 본인의 교육 수준은 어느 정도 입니까?

28. 직장에서의 업무는 당신의 교육 수준에 적절합니까? 